\title{
Grazing on a natural assemblage of ciliate and dinoflagellate cysts by the eastern oyster Crassostrea virginica
}

\author{
Agneta Persson $^{1,2}$, Barry C. Smith ${ }^{1, *}$ \\ ${ }^{1}$ NOAA, National Marine Fisheries Service, Northeast Fisheries Science Center, Milford Laboratory, 212 Rogers Ave., \\ Milford, Connecticut 06460, USA \\ ${ }^{2}$ Present address: Department of Marine Ecology, Göteborg University, Box 461, 40530 Göteborg, Sweden
}

\begin{abstract}
A natural dinoflagellate- and ciliate-cyst community from anoxic sediment collected from New Haven, Long Island Sound, was concentrated with a particle sorter and fed to oysters Crassostrea virginica. The total number of cysts and the species composition of cysts in beakers containing live oysters were measured before and after feeding by the oysters. The oysters significantly reduced the numbers of both dinoflagellate and ciliate cysts. Both empty cyst walls and filled (live) cysts were consumed. The oysters decreased the number of total cysts to less than half compared to control beakers containing empty oyster shells. Results from the experiment show that natural assemblages of cysts in sediment are degraded by the feeding activities of oysters. If toxic cysts were present in natural sediments resuspended from the bottom, digestion of resting cysts could lead to toxin accumulation in oysters. There was no major shift in species composition of cysts; cysts known as fossilizable were destroyed, as well as cysts not known to be very resistant or preservable.
\end{abstract}

KEY WORDS: Dinoflagellate $\cdot$ Cyst $\cdot$ Crassostrea virginica $\cdot$ Oyster $\cdot$ Grazing $\cdot$ Digesting

\section{INTRODUCTION}

Many kinds of organisms emerge from sediment that is placed in culturing conditions after a resting period in cold and darkness. Among them, dinoflagellates and ciliates are very common. In Persson (2002), more than 46 different ciliate taxa and at least 47 different dinoflagellate taxa were germinated from sediment samples from the Swedish west coast. In Fenchel et al. (1997), 20 ciliate species were detected initially, but during $130 \mathrm{~d}$ of culturing, an additional 115 cryptic species were recorded.

Approximately 10 percent of the dinoflagellate species worldwide are known to produce resting cysts, but in temperate areas this increases to nearly one-third (Nehring 1997, Persson et al. 2000). Among the cystproducers are many of the well-known, toxic species, for example paralytic shellfish poisoning (PSP)-producing Alexandrium spp. Resting cysts often are regarded as the over-wintering stage of coastal dinoflagellates; the cysts are formed at the end of the bloom and sink to the sea floor where they lay dormant before germinating when conditions again become suitable for vegetative growth (Anderson 1998, Dale 1983). Dinoflagellates that have a resting-cyst stage in their life history often spend most of the year as a resting cyst and only a brief period of a few weeks to months as vegetative cells (Dale 1983).

Other eukaryotic protists, such as ciliates, are known to produce cysts (Jones 1974), both division cysts (wherein cells divide by fission) and resting cysts. The resting cysts are thick-walled and can persist during adverse conditions; they are formed from vegetative cells as a strategy against environmental stresses, such as starvation (Gutiérrez et al. 2001).

Both ciliate and dinoflagellate cysts are known to be subjected to grazing by animals in nature (A. Persson pers. obs.). For example, resting cysts of dinoflagel- 
lates have been shown to be subjected to grazing (Persson \& Rosenberg 2003, Tsujino \& Uchida 2004, Persson et al. 2006, 2008, Persson \& Smith 2009). It is clear that all resting cysts produced in the water column are not still present and alive for the next season following several loss factors, including grazing (Persson et al. 2000).

A major problem in studies of the effect of deposit feeders on dinoflagellate cysts is the quantification of the amount the animals need to eat in order to produce a certain amount of fecal deposits. A number of dinoflagellate-cyst grazing studies have been published (Kremp et al. 2003, Montresor et al. 2003, Persson \& Rosenberg 2003, Tsujino \& Uchida 2004), but none have included quantitative measurements of cyst numbers. There are difficulties with the interpretation of relative abundance data; even if most cysts were digested, the cysts could be more highly concentrated in the pellets if the sediment consumed is rich in easily digested organic material. If empty cysts are more fragile than live cysts, one could get the impression that more cysts remain alive after grazing than before without a quantitative measurement. If cysts are picked from pellets for germination experiments, only those cysts that appear alive are chosen, not empty cyst walls. If there are no major changes in the species composition of cysts, then one cannot detect if cysts have been affected by grazing.

To address this quantitative problem, we used a filterfeeding bivalve, the eastern oyster Crassostrea virginica, as a model grazer. Oysters were placed in clean containers to which known quantities of cysts were added, and exact cyst contents were counted in the food and in the waste (feces and pseudofeces). To our knowledge, this is the first quantitative study of the effects of filtering bivalves on live dinoflagellate and ciliate cysts concentrated from natural sediment. Other types of resting stages were not studied here. Planktonic diatoms, for example, produce spores, but those are of a different size (much smaller) and accumulate differently in a particle separator; therefore, we did not count them.

\section{MATERIALS AND METHODS}

Dinoflagellate and ciliate cysts. Anoxic sediment was collected at $10.2 \mathrm{~m}$ depth in Morris Cove, New Haven

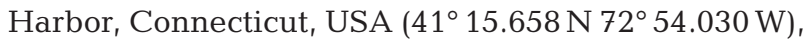
by divers. The uppermost $10 \mathrm{~cm}$ of the very fine-grained, black sediment was collected in buckets with lids.

For concentration of cysts, a sediment sorter designed for this purpose was used (Smith et al. 2009). A total of $16.5 \mathrm{l}$ of sediment was sorted over $48 \mathrm{~h}$ in cold $\left(6^{\circ} \mathrm{C}\right)$ and darkness; the most fine-grained material was collected (employing Stokes' Law) and immediately stored in a refrigerator $\left(4^{\circ} \mathrm{C}\right)$. To concentrate the cysts further for the experiment, the flask containing the sorted fraction was shaken thoroughly, and 11 of the slurry was removed. This slurry was sieved with cold-filtered seawater $(0.1 \mu \mathrm{m})$ to concentrate the size fraction of the dinoflagellate cysts (20 to $100 \mu \mathrm{m}$ ) and then transferred to a $100 \mathrm{ml}$ cylinder wherein the volume was adjusted to $100 \mathrm{ml}$. The sediment was kept as dark as possible during the process to prevent cyst germination.

Oysters. Crassostrea virginica from Long Island Sound were obtained 22 January 2003 from the Noank Aquaculture Cooperative in Groton, Connecticut. The oysters were kept in running, unfiltered seawater in the laboratory (Milford Laboratory, Milford, Connecticut) until use in the experiment (after $1 \mathrm{mo}$ ). The oysters were $30 \pm 3 \mathrm{~mm}$ in shell height. Temperature was increased gradually from ambient by $2^{\circ} \mathrm{C} \mathrm{d}^{-1}$ to $20^{\circ} \mathrm{C}$. Before the experiment, oysters were brushed in filtered seawater and placed in aerated, filtered seawater for $4 \mathrm{~d}$ to empty stomach contents.

Experimental setup. Fifteen 11 glass beakers were used in the experiment: 5 for feeding, 5 for controls, and 5 with unfed oysters. Two oysters were placed in each container on top of a stiff, plastic net (Fig. 1). The controls contained empty oyster shells to correct for any dinoflagellate cysts that may attach to the surface of experimental containers or otherwise become unre-

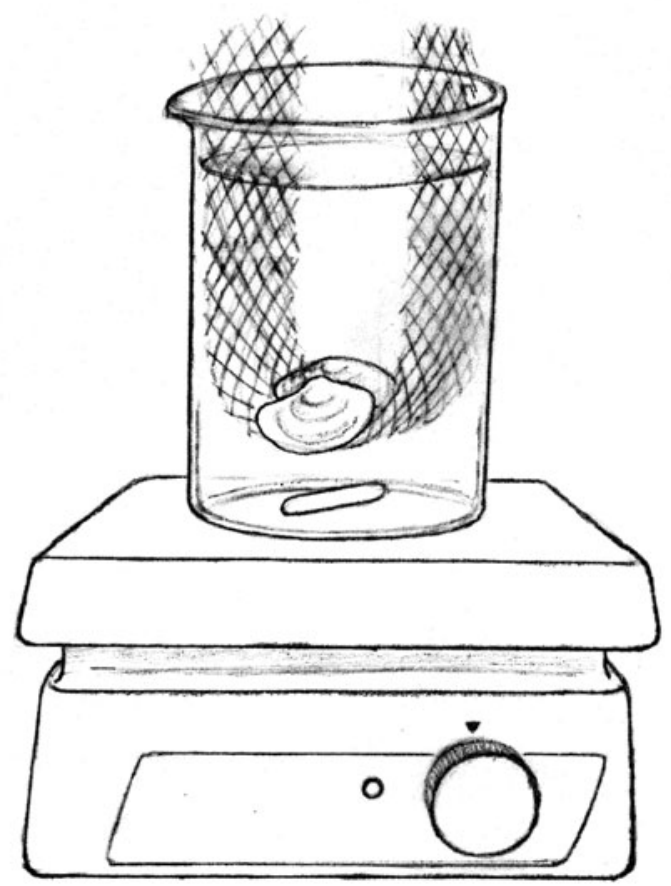

Fig. 1. Experimental setup used for the present and other studies (Persson et al. 2006). Two oysters are suspended on stiff plastic screen allowing free rotation of a stir bar in the bottom of the 11 beaker 
coverable. The same experimental setup was used to study grazing on culture-produced cysts of Alexandrium fundyense (Persson et al. 2006) and of Scrippsiella lachrymosa (Persson \& Smith 2009).

Two $\mathrm{ml}$ of the sorted dinoflagellate cyst fraction were added to each experimental beaker ( 5 with live oysters and 5 controls with empty oyster shells) and the rest was saved for measurement of initial dinoflagellate cyst concentration and species composition. Five samples of $2 \mathrm{ml}$ were used for preparation of permanent mounts, according to the description below, and observed microscopically to establish starting values.

The oysters were allowed to feed for $24 \mathrm{~h}$ at $18^{\circ} \mathrm{C}$ in darkness (covered with dark boxes). The sediment was kept suspended by gentle stirring with magnetic stir bars. At the end of the $24 \mathrm{~h}$ experiment, the temperature had increased to $28^{\circ} \mathrm{C}$ in the beakers because of friction from the stir bars, but the oysters were healthy and we concluded they had not been adversely affected by this. (In other experiments with the same setup, dark boxes were not used, and an insulating layer was used between stir plates and beakers, e.g. Persson et al. 2006.)

At the end of the experiment, each container was treated in the following way: the water was poured onto a $20 \mu \mathrm{m}$ screen, the container and oysters were cleaned with a plant sprayer (Spray Doc \#201P, Vermont American) and $0.1 \mu \mathrm{m}$ filtered seawater onto the same screen until the container and the oysters were considered to be clean of particles. Then the material on the screen was collected quantitatively in a beaker, sonicated for $5 \mathrm{~min}$ (Sonicor SC-50) to remove material sticking to spines of cysts, and sieved again on the $20 \mu \mathrm{m}$ screen, first with seawater, next with distilled water, and finally collected in a centrifuge tube. The tubes were placed in a $4^{\circ} \mathrm{C}$ refrigerator overnight.

To purge the oysters of any remaining cysts in the digestive system, they were returned to their respective containers with $1 \mathrm{l}$ of filtered seawater and given a drop of yellow, plastic microbeads (fluorescent microspheres; Fluoresbrite ${ }^{\circledR}$ YG Carboxylate Microspheres $2.00 \mu \mathrm{m})$ overnight. The subsequent day, all oysters had defecated yellow fecal pellets. The same procedure as above was repeated to recover any cysts present in the fecal material. This material was sieved, sonicated, and settled as described above.

For preparation of permanent mounts for cyst counting and identification, the water above the sediment in each centrifuge tube was removed carefully with a Pasteur pipette. The sediment in each tube was mixed, and $10 \mu \mathrm{l}$ of sediment was added to each of 5 slides (each tube corresponded to one beaker in the experiment) with a drop of glycerin. The slides were placed on a hot plate $\left(50^{\circ} \mathrm{C}\right)$ and the contents were spread evenly. When the water had evaporated, a coverglass was placed on top of the glycerin drop and the slide was sealed with beeswax. The amount of sediment in each tube was determined by weighing distilled water in the clean tubes up to a mark made with a permanent pencil at the sediment surface. Slides of material from fecal pellets (that contained very little material) were prepared by dividing the material evenly on a known number of slides (5 or 6 ) to a desired density for counting. Otherwise fecal pellet samples were prepared the same way as sediment. Whole slides were counted (1 entire slide per container and per pellet sample).

\section{RESULTS}

The total number of cysts was significantly $(\mathrm{p}=$ 0.0001 ) reduced by oyster grazing (Fig. 2) to one-third of initial values and to less than half compared to the empty shell control (reduced by 57.5\%). The control still contained $84 \%$ of the cysts from the start of the experiment, but the number of full (live) cysts had declined through germination; approximately $52 \%$ of the full cysts had germinated in the control (Fig. 2). When only full cysts are considered, a comparison between control and oyster treatment reveals that $43.8 \%$ of the full cysts were eliminated by oyster grazing activities. This, however, is probably an underestimation of the actual number of digested live cysts as many of the living cysts germinated in the control but were ingested long before they had time to germinate in the oyster treatment. Unfed live oyster treatments developed no cysts, full or otherwise, and no germinated cells.

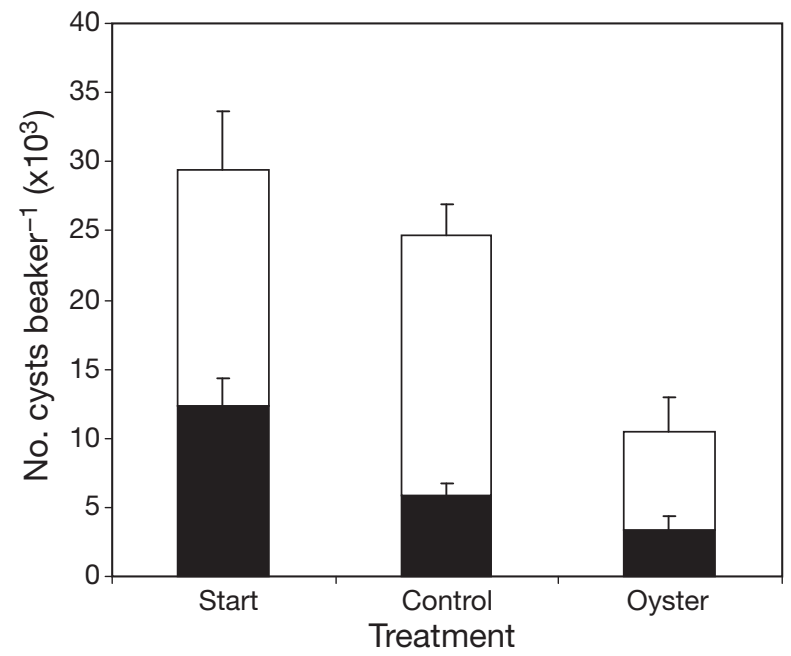

Fig. 2. Number of cysts per beaker (5 replicates/treatment). Filled (live) cysts are in black and empty cysts are in white. Error bars are SD of numbers of filled cysts (black) and total cysts (white). Start: total cysts in each treatment; control: empty shell treatments; oyster: filtering oysters 


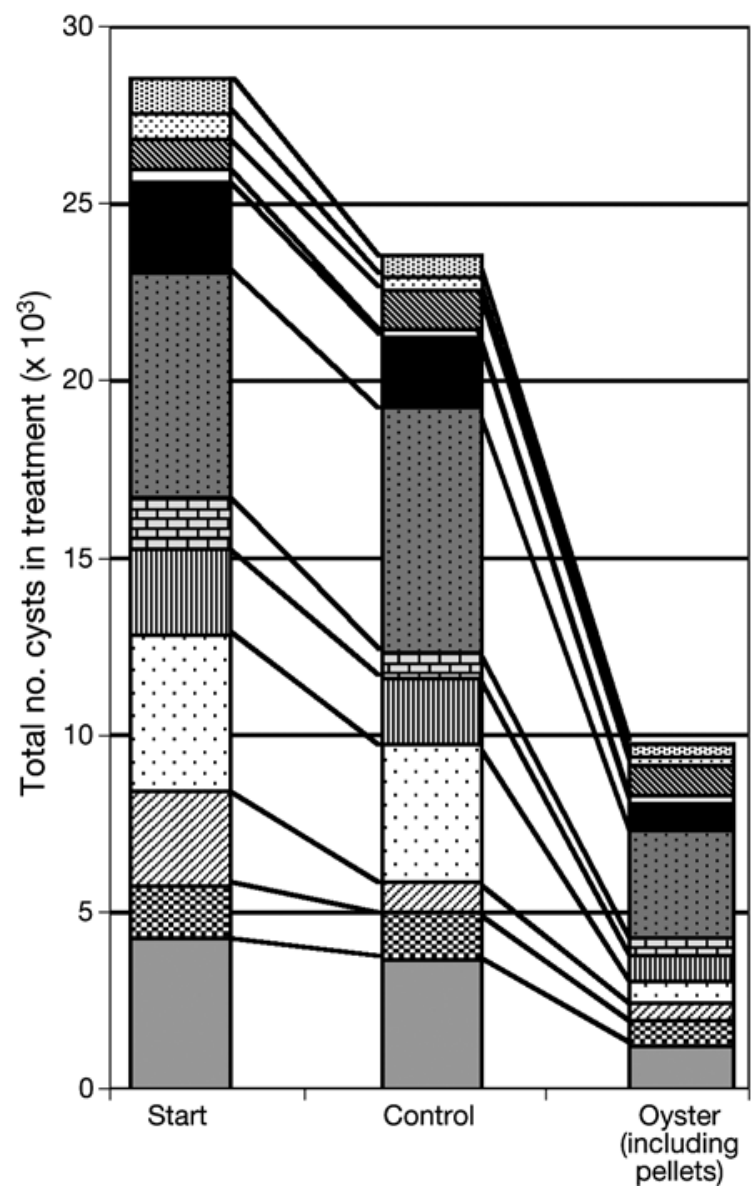

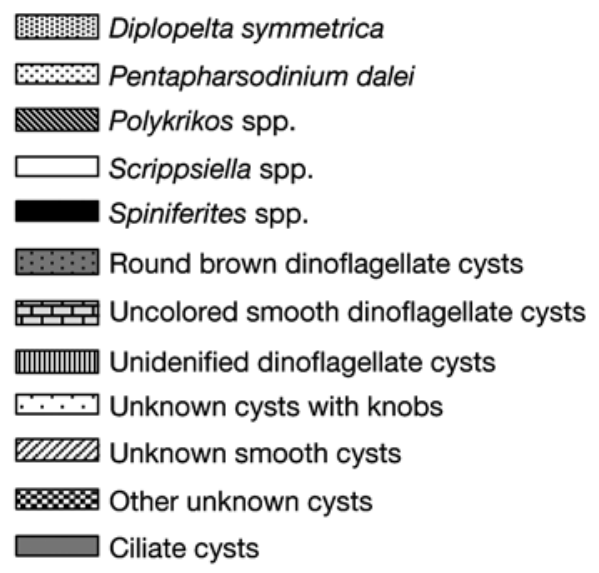

Fig. 3. Species composition throughout the experiment. Values are averages of 5 replicates for each treatment stacked in order as listed. Start: total cysts in each treatment; control: empty shell treatments; oyster: filtering oysters. Minor cyst types have been omitted; see Table 1 for a complete list
In Fig. 3 and Table 1 the cyst species composition is shown. There was a slight shift in species composition of cysts attributable to grazing: the proportion of cysts known to be fossilizable increased while cysts unknown as fossils decreased. Cysts of fossilizable species that are known to have hard and resistant walls (e.g. round, brown cysts of Protoperidinium spp. and Diplopsalis-like species and Spiniferites spp.), however, were reduced in numbers, as were cysts not known to have walls preservable over long time scales (e.g. smooth, uncolored cysts). Some cysts were easily germinated in the control: e.g. Pentapharsodinium dalei, Plykrikos spp., Diplopelta symmetrica, unidentified, uncolored dinoflagellate cysts, and ciliate cysts.

No significant changes in diversity of dinoflagellate cysts were found between experimental treatments $(\mathrm{p}=0.05)$; approximately 30 different cyst species were found both before (mean $\pm \mathrm{SD}, 32.8 \pm 3.9$ ) and after $(28.6 \pm 4.0)$ grazing. The control had $32.8 \pm 3.3$ different cyst species. No cyst species could be shown to disappear completely after grazing (although pellet samples contained fewer species [24.2 \pm 5.4$]$, but these samples were small).

\section{DISCUSSION}

The present study demonstrates clearly that benthic, protistan cysts are eaten and destroyed by the eastern oyster, and that empty cyst walls of fossilizable species, as well as unfossilizable cysts, are destroyed. This experiment has shown that Crassostrea virginica, when offered only this diet, reduced the number of cysts from the sediment to less than half of initial values in only $24 \mathrm{~h}$ of feeding. In nature, cysts are constantly grazed by filter feeders and deposit feeders, providing they are present in an oxic environment where animals can live. It is possible that the presence of sand grains causes a larger reduction in viable cysts through grinding, as in experiments with cultured cysts there was a smaller reduction in cyst numbers (Persson et al. 2006, Persson \& Smith 2009). As much as $52 \%$ of the filled cysts germinated during the experiment. As oysters from the same batch in other experiments cleared the same amount of sediment and cultured cysts within a few hours, it is unlikely that many cysts had time to germinate before being filtered by the oysters; however, cysts in the control remained in conditions favorable for germination during the entire $24 \mathrm{~h}$ experi- 
Table 1. Relative abundance of cysts. Start: total cysts in each treatment; control: empty shell treatments; oyster: filtering oysters; pellet: cysts in oyster feces

\begin{tabular}{|lllll|}
\hline Relative abundance (\%) & Start & Control & Oyster & Pellet \\
\hline Diplopelta symmetrica & $3.4 \pm 2.0$ & $2.4 \pm 0.5$ & $3.7 \pm 2.3$ & $5.1 \pm 3.9$ \\
Gymnodinium catenatum (cf.) & $0.1 \pm 0.1$ & $0.1 \pm 0.2$ & $0.7 \pm 0.7$ & $0.3 \pm 0.6$ \\
Lingulodinium polyedrum & $0.4 \pm 0.6$ & $0.2 \pm 0.3$ & $0.3 \pm 0.4$ & $0.3 \pm 0.4$ \\
Pentapharsodinium dalei & $2.7 \pm 0.7$ & $1.4 \pm 1.3$ & $2.5 \pm 2.5$ & $2.6 \pm 0.9$ \\
Polykrikos spp. & $2.9 \pm 0.9$ & $4.5 \pm 0.5$ & $9.0 \pm 3.1$ & $6.0 \pm 3.0$ \\
Protoceratium reticulatum & $1.1 \pm 1.2$ & $1.6 \pm 0.9$ & $1.9 \pm 1.3$ & $1.4 \pm 0.8$ \\
Protoperidinium americanum & $0.2 \pm 0.3$ & $0.4 \pm 0.3$ & $0.9 \pm 0.8$ & $0.5 \pm 0.7$ \\
Protoperidinium compressum & $0.1 \pm 0.1$ & $0.2 \pm 0.3$ & $0.1 \pm 0.2$ & $0.3 \pm 0.7$ \\
Protoperidinium conicoides & $0.0 \pm 0.0$ & $0.1 \pm 0.2$ & $0.0 \pm 0.0$ & $0.1 \pm 0.3$ \\
Protoperidinium monospinum & $0.3 \pm 0.2$ & $0.2 \pm 0.4$ & $0.4 \pm 0.4$ & $0.1 \pm 0.3$ \\
Protoperidinium nudum & $0.0 \pm 0.0$ & $0.0 \pm 0.0$ & $0.4 \pm 0.8$ & $0.0 \pm 0.0$ \\
Protoperidinium oblongum & $0.3 \pm 0.4$ & $0.4 \pm 0.5$ & $0.8 \pm 1.2$ & $1.0 \pm 0.7$ \\
Scrippsiella spp. & $1.0 \pm 0.8$ & $0.9 \pm 0.7$ & $1.6 \pm 1.2$ & $0.0 \pm 0.0$ \\
Spiniferites spp. & $8.7 \pm 1.8$ & $8.3 \pm 3.4$ & $7.9 \pm 4.4$ & $8.7 \pm 3.0$ \\
Round, brown dinoflagellate cysts & $22.2 \pm 3.4$ & $27.7 \pm 3.6$ & $28.9 \pm 1.9$ & $32.5 \pm 3.4$ \\
Uncolored, smooth dinoflagellate cysts & $4.8 \pm 2.3$ & $3.1 \pm 2.4$ & $4.9 \pm 2.9$ & $3.4 \pm 4.0$ \\
Unidentified dinoflagellate cysts & $12.5 \pm 12.1$ & $7.6 \pm 4.6$ & $6.9 \pm 4.1$ & $5.6 \pm 3.3$ \\
Unknown cysts with knobs & $13.3 \pm 7.8$ & $14.8 \pm 13.1$ & $7.5 \pm 4.2$ & $9.0 \pm 5.5$ \\
Unknown smooth cysts & $10.7 \pm 5.3$ & $4.8 \pm 3.0$ & $6.2 \pm 6.7$ & $7.5 \pm 6.0$ \\
Other unknown cysts & $1.2 \pm 0.5$ & $6.4 \pm 7.5$ & $1.3 \pm 1.0$ & $3.7 \pm 3.5$ \\
Ciliate cysts & $14.1 \pm 5.3$ & $15.0 \pm 8.2$ & $14.1 \pm 11.0$ & $11.6 \pm 2.7$ \\
& & & & \\
\hline
\end{tabular}

ment. Cysts from anoxic sediments germinate very easily when transferred to culturing conditions, provided that the period of dormancy has passed and the cysts are in a state of quiescence (Anderson 1998, Persson 2002), awaiting suitable conditions for germination and continued growth. The presence of oxygen is thought to be the most important germination cue, but light is also known to trigger germination as well as a rise in temperature (Anderson 1998).

Some empty cysts that were found in initial samples could have been broken into smaller pieces from the stirring in the experiment and then sieved away during the rinsing process. This could account for some of the difference between initial and control numbers. Additionally, some cysts are not easily identified when they are empty (e.g. many of the round, uncolored cysts), which may also have caused some differences in cyst numbers found between initial and $24 \mathrm{~h}$ samples.

Anoxic sediments are known to have a different dinoflagellate-cyst composition than sediment from aerobic areas (Montresor et al. 1994, Zonneveld et al. 1997). Anoxic sediment was chosen for this feeding experiment based upon the assumption that the differences in species composition of dinoflagellate cysts between aerobic and anaerobic areas are caused, at least in part, by differences in the consumption and/or digestion of dinoflagellate cysts by animals (Persson et al. 2000, Persson \& Rosenberg 2003). In anoxic sediment, cysts cannot be extensively modified by digestive processes of animals in the sediment, although some may have been subjected to zooplankton feeding while sinking. Cysts embedded in fecal pellets, however, would likely have been excluded from the fraction collected on the particle separator; thus it is reasonable to assume that the majority of cysts in the anoxic sediment used had not been previously consumed by other organisms.

There are 2 different views (research initiatives) of cysts that are of interest: the survey view and the bloom view. In a cyst survey, all cysts are of interest, not only live cysts. Some dinoflagellate cysts can only be identified to species level when empty (the opening, or archaeopyle, has a species-specific shape, but the cyst is simply round and brown when intact and alive). Surveys are very important for mapping the presence of species and it makes it possible to find dinoflagellate species that have a short bloom or are difficult to identify as free-living. For areas in which there is no current plankton survey program, dinoflagellate cyst surveys are crucial to find toxic species, such as Alexandrium spp. or Gymnodinium catenatum. With a bloom view it is important to consider such factors as cyst production, preservation, and germination. Mostly this is of interest for species that cause harmful or toxic blooms. Accordingly, the dynamics of Alexandrium fundyense blooms in the Gulf of Maine have been studied extensively (Anderson et al. 2005, McGillicuddy et al. 2005).

Information on ciliate resting cysts and literature on their identification is sparse, but growing. Recent information can be found in Gutiérrez et al. (2001), Kim et 
al. (2002), Calvo et al. (2003) and Xu \& Foissner (2005), and several tintinnid cysts were described by Reid \& John (1978). Tintinnid cysts are often flask-shaped and closed with a plug in the opening from which the cell emerges during excystment (Reid \& John 1978, Xu \& Foissner 2005). Other ciliate cysts can be round with spines (e.g. Stylonychia) or round and uncoloured (e.g. Euplotes), and some ciliate cysts are often mistaken for dinoflagellate cysts (unidentified species or round, colorless cysts). Studies have been made on germination of cysts or emergence of cryptic cells from sediment samples (Fenchel et al. 1997, Finlay 1998, Persson 2002). In these studies, the germinated and/or emerging ciliates were identified, but the appearance and identity of different cyst types remained unknown. Both ciliate and dinoflagellate cysts can thus be smooth, colorless, light- to dark-brown, they can have spines of different shape and size, and they can have a cover of mucus to which debris attaches. These are most probably species-specific characters, not only for dinoflagellate but also for ciliate cysts (Xu \& Foissner 2005). Most ciliate cysts remain unidentified. Approximately 200 dinoflagellate cysts have been identified (Dale 1983), but many remain unidentified.

A strong correlation has been shown between PSP toxicity levels in shoreline mollusks and abundance of toxic Alexandrium spp. cysts in sediments (Turgeon et al. 1990). The possibility that cysts sometimes may be the direct cause of toxicity in shellfish has been suggested by many authors (e.g. Yentsch \& Mague 1979, White \& Lewis 1982, Shumway et al. 1988, Anderson 1997, Bravo et al. 1998). Recently, Persson et al. (2006) showed that ingestion of toxic Alexandrium fundyense cysts caused accumulation of toxins in the eastern oyster Crassostrea virginica. The experiment in the present study showed that dinoflagellate cysts from natural sediments are ingested and digested by the same animal under the same experimental conditions (the same batch of oysters, experimental setup, room, etc.). There is no reason to believe that toxic cysts, if present in natural sediments, would escape or resist the action of suspension-feeding animals when sediment is resuspended. Thus, toxic dinoflagellate cysts can cause toxicity in shellfish at the decline of the bloom, when the cysts sink to the sediment, or even directly from the sediment. From these findings, it appears that a substantial reduction in numbers of toxic cysts may occur over time due to repeated grazing on cysts in oxygenated sediments, whereas anoxic sediment could act as a trap, preserving cysts of toxic (and other) species until they are resuspended by upwelling or a storm.

Acknowledgements. This research was performed while A.P. held a National Research Council Research Associateship Award at the National Oceanic and Atmospheric Administra- tion, National Marine Fisheries Service laboratory in Milford, Connecticut. We are very grateful to G. H. Wikfors for comments on the manuscript; to J. Alix for laboratory assistance; to M. S. Dixon, NOAA Diving Program, for diving for mud; to Capt. R. Alix and the RV 'Victor Loosanoff'; and to K. Rivara, Noank, Connecticut Aquaculture facility. Mention of trade names does not imply endorsement.

\section{LITERATURE CITED}

Anderson DM (1997) Diversity of harmful algal blooms in coastal waters. Limnol Oceanogr 42:1009-1022

Anderson DM (1998) Physiology and bloom dynamics of toxic Alexandrium species, with emphasis on life cycle transitions. In: Anderson DM, Cembella AD, Hallegraeff GM (eds) The physiological ecology of harmful algal blooms. Springer-Verlag, Heidelberg, p 29-48

Anderson DM, Stock CA, Keafer BA, Nelson BA and others (2005) Alexandrium fundyense cyst dynamics in the Gulf of Maine. Deep-Sea Res II 52:2522-2542

Bravo I, Franco JM, Reyero MI (1998) PSP toxin composition of three life cycle stages of Gymnodinium catenatum. In: Reguera B, Blanco J, Fernández ML, Wyatt T (eds) Harmful algae. Xunta de Galicia and IOC of UNESCO, Grafisant, Santiago de Compostela, p 356-358

> Calvo P, Fernandez-Aliseda MC, Garrido J, Torres A (2003) Ultrastructure, encystment and cyst wall composition of the resting cyst of peritrich ciliate Ophistonecta henneguyi. J Eukaryot Microbiol 50:49-56

Dale B (1983) Dinoflagellate resting cysts: 'benthic plankton'. In: Fryxell GA (ed) Survival strategies of the algae. Cambridge University Press, Cambridge, p 69-136

Fenchel T, Esteban GF, Finlay BJ (1997) Local versus global diversity of microorganisms: cryptic diversity of ciliated protozoa. Oikos 80:220-225

Finlay BJ (1998) The global diversity of protozoa and other small species. Int J Parasitol 28:29-48

> Gutiérrez JC, Callejas S, Borniquel S, Benítez L, MartínGonzález A (2001) Ciliate cryptobiosis: a microbial strategy against environmental starvation. Int Microbiol 4:151-157

Jones AR (1974) The ciliates. Hutchinson, London

- Kim YO, Suzuki T, Taniguchi A (2002) A new species in the genus Cyrtstrombidium (Ciliophora, Oligotrichia, Oligotrichida): its morphology, seasonal cycle and resting stage. J Eukaryot Microbiol 49:338-343

> Kremp A, Shull DH, Anderson DM (2003) Effects of depositfeeder gut passage and fecal pellet encapsulation on germination of dinoflagellate resting cysts. Mar Ecol Prog Ser 263:65-73

McGillicuddy DJ, Anderson DM, Lynch DR, Townsend DW (2005) Mechanisms regulating large-scale seasonal fluctuations in Alexandrium fundyense populations in the Gulf of Maine: results from a physical-biological model. DeepSea Res II 52:2698-2714

Montresor M, Montesarchio E, Marino D, Zingone A (1994) Calcareous dinoflagellate cysts in marine sediments of the Gulf of Naples (Mediterranean Sea). Rev Palaeobot Palynol 84:45-56

Montresor M, Nuzzo L, Mazzocchi MG (2003) Viability of dinoflagellate cysts after the passage through the copepod gut. J Exp Mar Biol Ecol 287:209-221

Nehring S (1997) Dinoflagellate resting cysts from recent German coastal sediments. Bot Mar 40:307-324

Persson A (2002) Proliferation of cryptic protists and germination of resting stages from untreated sediment samples with emphasis on dinoflagellates. Ophelia 55:151-166 
Persson A, Rosenberg R (2003) Impact of grazing and bioturbation of marine benthic deposit feeders on dinoflagellate cysts. Harmful Algae 2:43-50

Persson A, Smith BC (2009) Consumption of Scrippsiella lachrymosa resting cysts by the eastern oyster (Crassostrea virginica). J Shellfish Res 28:221-225

Persson A, Godhe A, Karlson B (2000) Dinoflagellate cysts in recent sediments from the west coast of Sweden. Bot Mar 43:69-79

Persson A, Smith BC, Wikfors GH, Quilliam M (2006) Grazing on toxic Alexandrium fundyense cysts and vegetative cells by the eastern oyster (Crassostrea virginica). Harmful Algae 5:678-684

Persson A, Smith BC, Dixon M, Wikfors GH (2008) The eastern mud snail, Ilyanassa obsoleta, actively forages for, consumes, and digests cysts of the dinoflagellate, Scrippsiella lachrymosa. Malacologia 50:341-345

Reid PC, John AWG (1978) Tintinnid cysts. J Mar Biol Assoc UK 58:551-557

Shumway SE, Sherman-Caswell S, Hurst JW (1988) Paralytic shellfish poisoning in Maine: monitoring a monster. J Shellfish Res 7:643-652

Smith BC, Persson A, Wikfors GH (2009) A particle separator used to collect dinoflagellate cysts from bottom material. Limnol Oceanogr Methods 7:521-526

Submitted: May 23, 2008; Accepted: May 8, 2009
Tsujino M, Uchida T (2004) Fate of resting cysts of Alexandrium spp. ingested by Perinereis nuntia (Polychaeta) and Theola fragilis (Mollusca). J Exp Mar Biol Ecol 303: $1-10$

Turgeon J, Cembella AD, Therriault JC, Beland P (1990) Spatial distribution of resting cysts of Alexandrium spp. in sediments of the lower St. Lawrence estuary and the Gaspé coast (eastern Canada). In: Graneli E, Sundström L, Edler L, Anderson DM (eds) Toxic marine phytoplankton. Elsevier, New York, p 238-243

White AW, Lewis CM (1982) Resting cysts of the toxic, red tide dinoflagellate Gonyaulax excavata in Bay of Fundy sediments. Can J Fish Aquat Sci 39:1185-1194

Yentsch CM, Mague FC (1979) Motile cells and cysts: two probable mechanisms of intoxication of shellfish in New England waters. In: Taylor DL, Seliger HH (eds) Toxic dinoflagellate blooms. Elsevier, New York, p 127-130

Zonneveld KAF, Versteegh GJM, de Lange GJ (1997) Preservation of organic-walled dinoflagellate cysts in different oxygen regimes: a 10,000 year natural experiment. Mar Micropaleontol 29:393-405

> Xu K, Foissner W (2005) Descriptions of Protospathidium serpens (Kahl, 1930) and P. fraterculum n. sp. (Ciliophora, Haptoria), two species based on different resting cyst morphology. J Eukaryot Microbiol 52:298-309

Proofs received from author(s): June 19, 2009 